\title{
IOT Based Automatic Water Container Filler Using Arduino
}

\author{
${ }^{1}$ Ashish Mishra, ${ }^{2}$ Sarvgya Yadav, ${ }^{3}$ Shweta Singh, ${ }^{4}$ Vineet Pandey, ${ }^{5}$ Vishal Dwivedi, ${ }^{6}$ Deepti Ojha \\ $1,2,3,4,5$ Student, Department of ECE, ITM, GIDA, Gkp, UP, India \\ ${ }^{6} \mathrm{Head}$ of Department, Department of ECE, ITM, GIDA, Gkp, UP, India
}

\begin{abstract}
The objective of our project is to design, develop and monitor "Automatic Water Container Filler using Arduino". This work provides with a lot of benefits like low power feeding, low functioning cost, less care, accuracy and many more. This project is based on automation and is a vast application IOT concept. A prototype has been developed to illustrate the project. Feeding the container in hand to hand is the main task that is carried out by a machine and this process is commonly used by many Robot.
\end{abstract}

Keywords:- IOT, Automation, Sensors, Arduino, 555 Timer.

\section{INTRODUCTION}

In this paper, This Project is based on the concept of IOT (Internet of Things). The cyberspace of things, or IOT, is a system of unified calculating devices, mechanical and digital machines, objects, animals or people that are provided with sole identifiers (UIDs) and the ability to transfer data over a network without requiring human-tohuman or human-to-computer communication. With this concept, few more concept is also required for our Project i.e,

$>$ The concept of $\mathrm{I} 2 \mathrm{C}$

$>$ How to govern DC motor through Arduino?

$>$ How to govern ultrasonic sensors through Arduino?

$>$ What is the function of LDR sensor and how it works?

What is the function of timer and how it works?

This Project is to feed the water filled container in hand to hand or to the particular position with the help of the above mention concept. This Project consists of -

$>$ Electronic System

$>$ Software Controlled by Arduino UNO

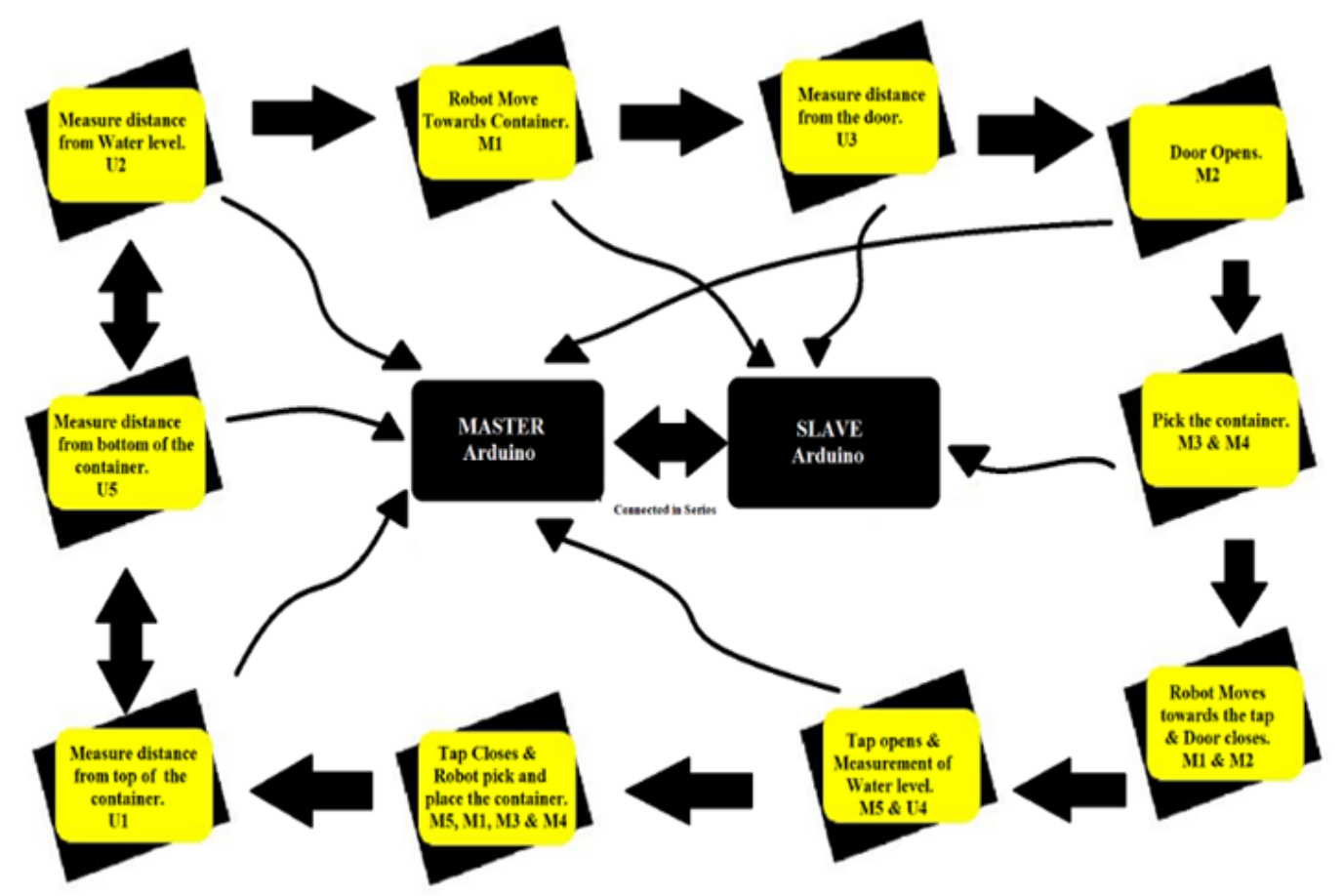

Fig 1. Block Diagram

\section{BLOCK DIAGRAM}

There are two Arduino UNO board which are connected in series by using the concept of $\mathrm{I} 2 \mathrm{C}$ and all the control of the system id done through these two Arduino. Arduino 1 acts as Master Arduino and Arduino 2 acts as Slave. Ultrasonic Sensor US1, US2, US5, US4 and Motor
M2, M5 are connected to Master Arduino. Ultrasonic Sensor US3 and Motor M1, M3, M4 are connected to Slave Arduino.

After the measurement of water level and height of the container with the help of US1, US2, US5 message is send to Robot. If the container is empty of half filled, M1 
comes into function and moves towards the container. When it comes near the door M2 starts working and door opens automatically and the distance between robot and door is measured by US3, which is attached in the front of the robot. Then Robot moves towards the container and Robotic Arm M3, M4 comes into function and pick the container and put it under the tap. When it comes under the tap US4 continuously measure the water level and M5 starts, which moves downwards with the help of rack pinion and comes in between the LDR and Led, this makes the tap to open due to trigger in 555 timer. When container is filled completely Again Robot pick and place it at its position.

\section{THEORY}

\section{A. Arduino UNO}

Arduino is an open-source microchip technology platform based on easy-to-use hardware and software. The Arduino Uno is a microcontroller board based on the ATmega328. It has 20 digital input/output pins (of which 6 can be used as PWM outputs and 6 can be used as analog inputs), a $16 \mathrm{MHz}$ resonator, a USB connection, a power jack, an in-circuit system programming (ICSP) header, and a reset button. It contains everything needed to support the microcontroller; simply connect it to a computer with a USB cable or power it with a AC-to-DC adapter or battery to get started.

The Uno differs from all previous boards in that it does not use the FTDI USB-to-serial driver chip. Instead, it features an ATmega16U2 programmed as a USB-to-serial converter. This auxiliary microcontroller has its own USB bootloader, which allows forward-thinking users to reprogram it.

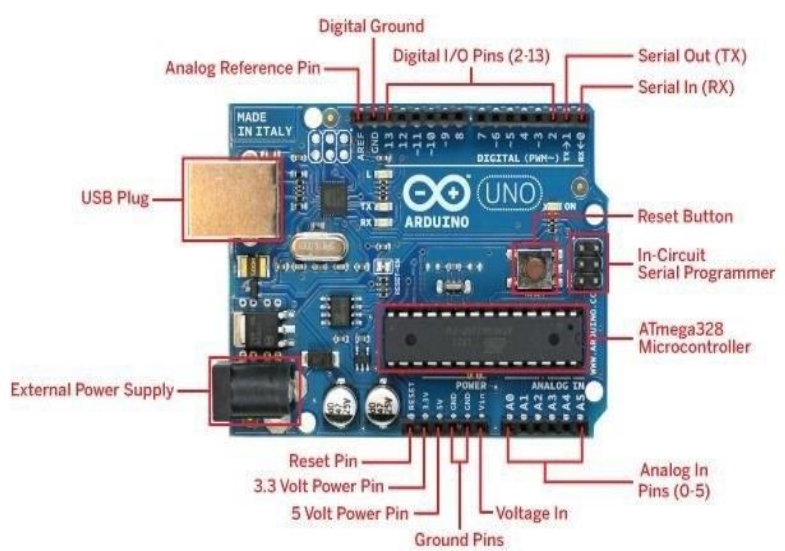

Fig 2. Arduino UNO Board

\section{B. Sensors}

> Ultrasonic Sensor:

Ultrasonic sensors calculate distance by using ultrasonic waves. The sensor head emits an ultrasonic wave and receives the wave reflected back from the target. Ultrasonic Sensors measure the distance to the target by measuring the time between the emission and reception.

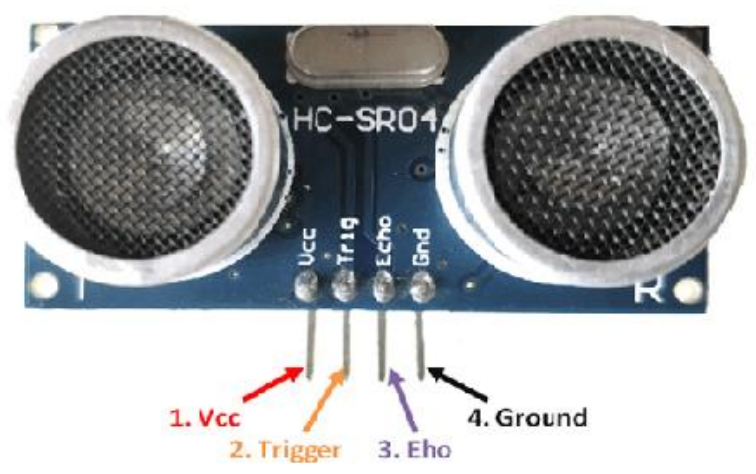

Fig 3. Ultrasonic Sensor

\section{LDR Sensor:}

An LDR or light dependent resistor is also known as photo resistor, photocell, photoconductor. It is a one type of resistor whose resistance varies depending on the quantity of light falling on its surface. When the light falls on the resistor, then the resistance changes. These resistors are often used in many circuits where it is required to sense the existence of light.

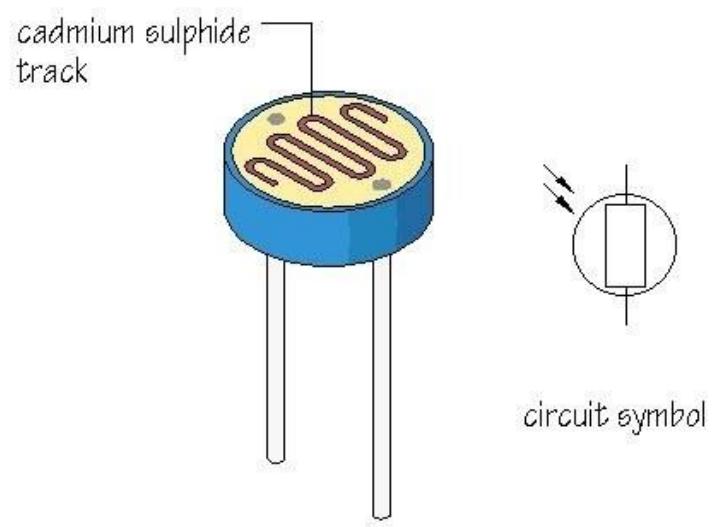

Fig 4. LDR Sensor

\section{555 Timer}

555 timer is used in almost every electronic circuit today. For a 555 timer working as a flip flop or as a multivibrator, it has a particular set of arrangements. It operates from a wide range of power ranging from +5 Volts to +18 Volts supply voltage. Sinking or sourcing $200 \mathrm{~mA}$ of load current. The external components should be selected properly so that the timing breaks can be made into several minutes along with the frequencies more than several hundred kilohertz. 


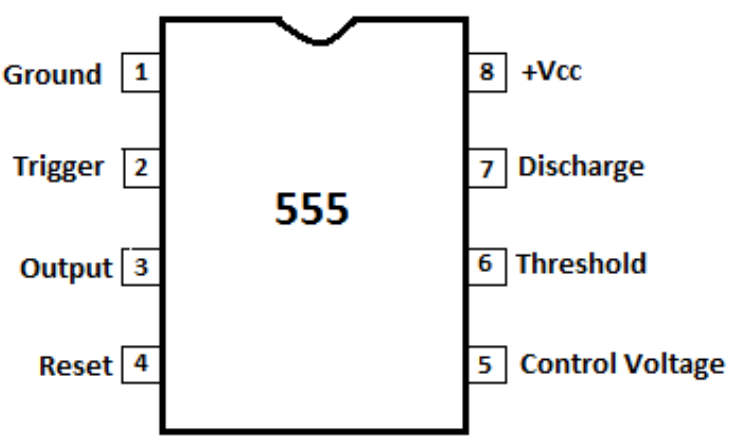

Fig 5. Pin Diagram Of 555 Timer

\section{DC Geared Motor}

The motor we have used is Center shaft $100 \mathrm{rpm} \mathrm{dc}$ geared motors specifically designed for robotic applications .It is very easy to use. It has Nut and threads on shaft to easily connect and internal threaded shaft for easily connecting it to wheel. Easy to use and mount, long durability and very affordable considering the features. These motors open a wide choice for us in terms of rolls and chassis.

These motors are simple DC Motors containing gears for the shaft for obtaining the optimal performance characteristics. They are known as Center Shaft DC Geared Motors because their shaft covers through the center of their gear box assembly.

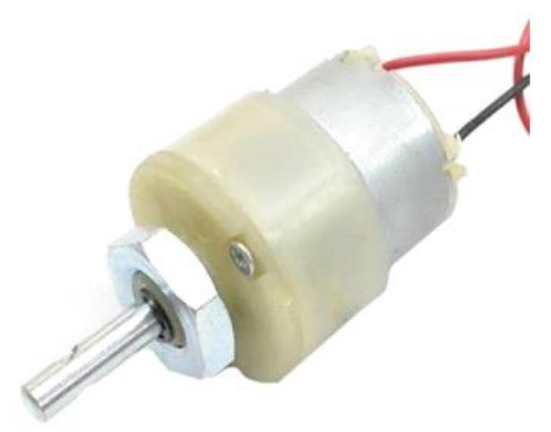

Fig 6. DC Geared Motor

\section{E. L293D Motor Driver}

L293D is a typical Motor driver or Motor Driver IC which allows DC motor to drive on either direction. L293D is a 16-pin IC which can control a set of two DC motors at once in any direction. It means that you can control two DC motor with a single L293D IC. It works on the concept of H-bridge.

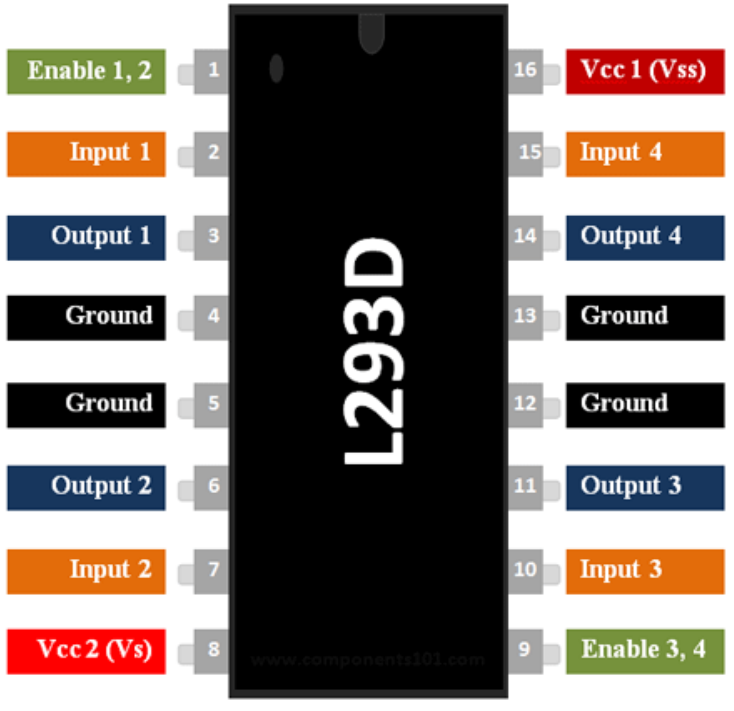

Fig 7. Pin Description of L293D

\section{COMPLETE PROJECT SYSTEM}

\section{A. Mechanism}

Firstly, Level of the Water and height of the container is measured. If the water level is less than half, then robot will move towards the container. When robot comes near the container door open automatically and robotic arm pick the container ant put it under the tap. Vertical level indicator comes into function and tap opens automatically. When water filled into container Robot and robotic arm again pick it up and place it at its position.

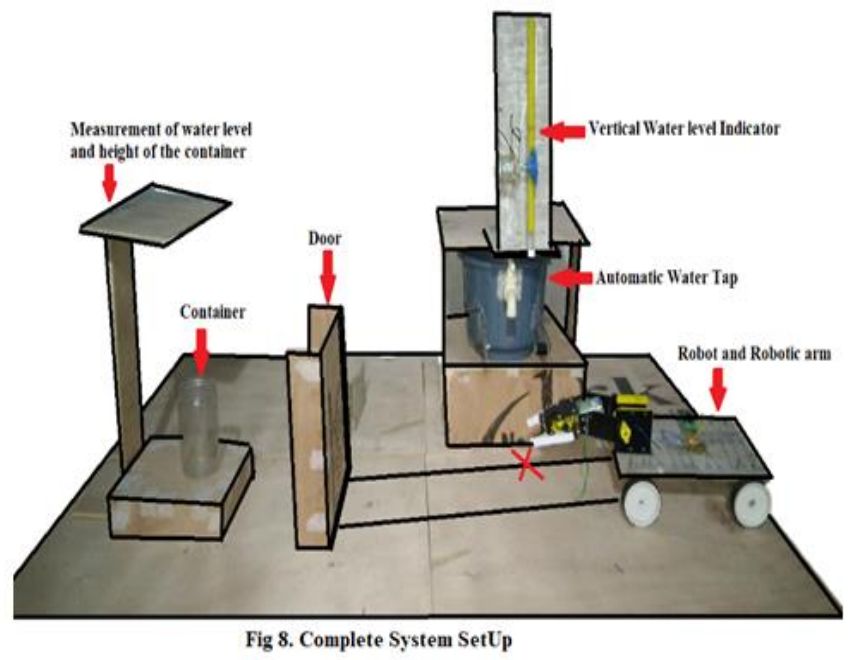

\section{B. Software Implementation}

The software part programming done through Arduino Uno software (IDE). It is easy to write code and upload it to the board. $\mathrm{C}$ and $\mathrm{C}++$ language are used for programming. In this project, programming is done in two phase. Firstly, program for Master Arduino had been written. Then after program for Slave Arduino had written. And the link between these two Arduino is done by using the concept of I2C. 


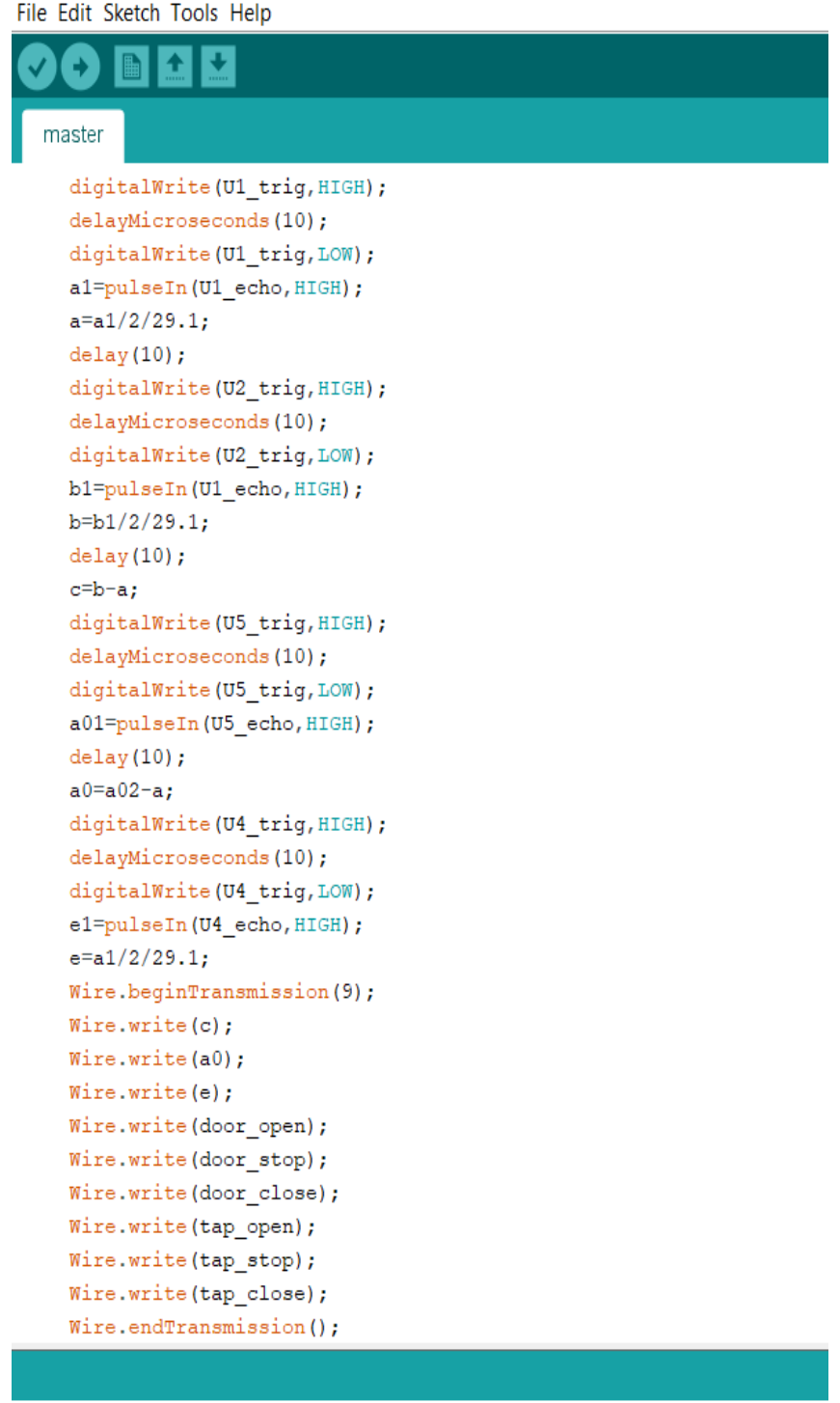

Fig 9. Master Arduino Programming View
File Edit Sketch Tools Help

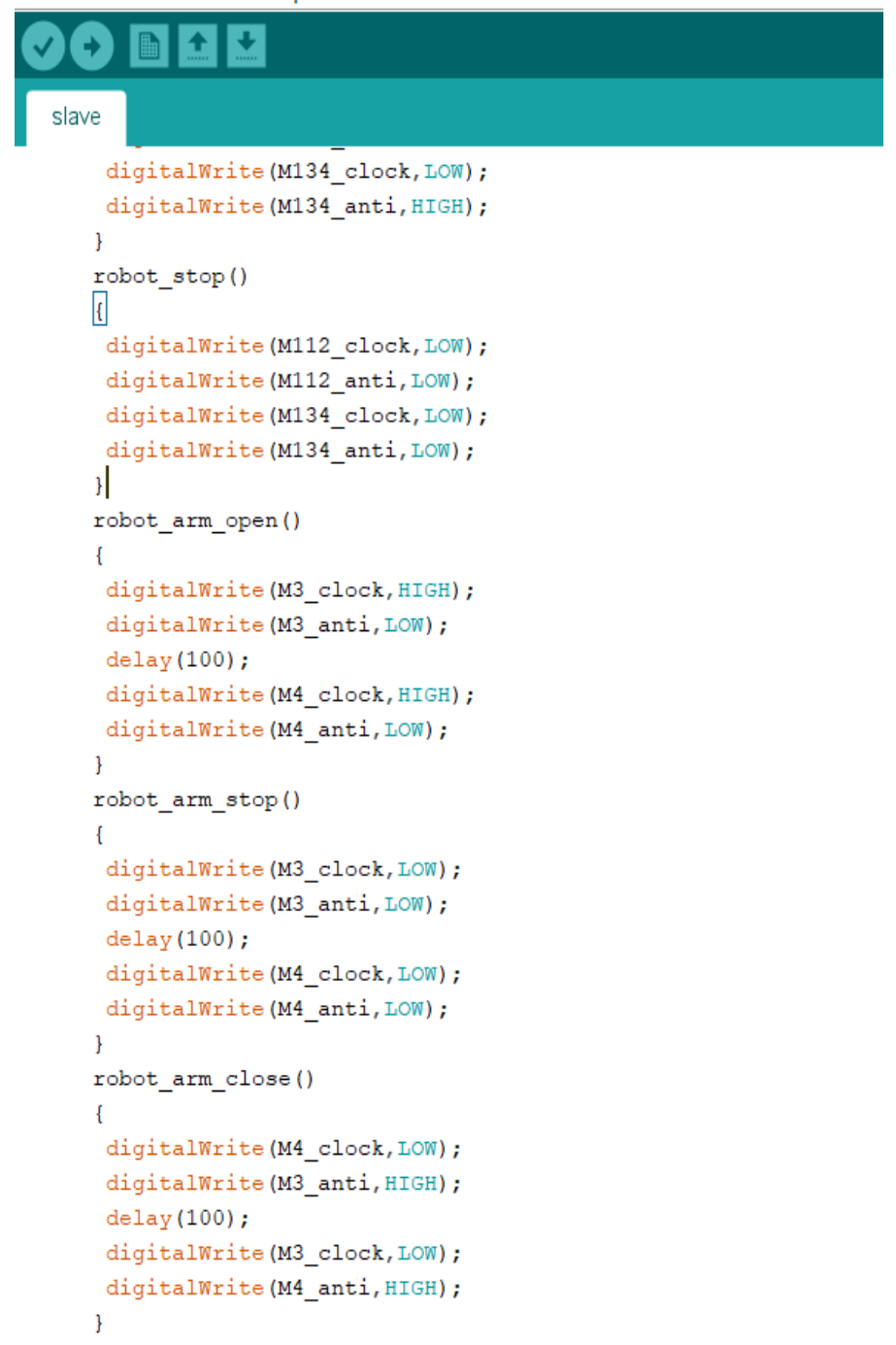

Fig 10. Slave Arduino Programming View

\section{Connection}

The connection of Ultrasonic Sensor with Arduino are as follows:

$>$ Vec to 5V Pin of the Arduino UNO board.

$>$ Gnd to Gnd Pin of the Arduino UNO board.

$>$ Trig to Digital Pin of the Arduino UNO board.

Echo to Digital Pin of the Arduino UNO board.

The connection of DC Geared Motor using interface of L293D with Arduino are as follows:

$>$ Connect $5 \mathrm{~V}$ and ground of the $\mathrm{IC}$ to $5 \mathrm{~V}$ and ground of Arduino.

Connect the motor to pins 2 and 3 of the IC.

$>$ Connect IN1 of the IC to pin 8 of Arduino.

$>$ Connect IN2 of the IC to pin 9 of Arduino.

$>$ Connect EN1 of IC to pin 2 of Arduino.

$>$ Connect SENS A pin of IC to the ground. 


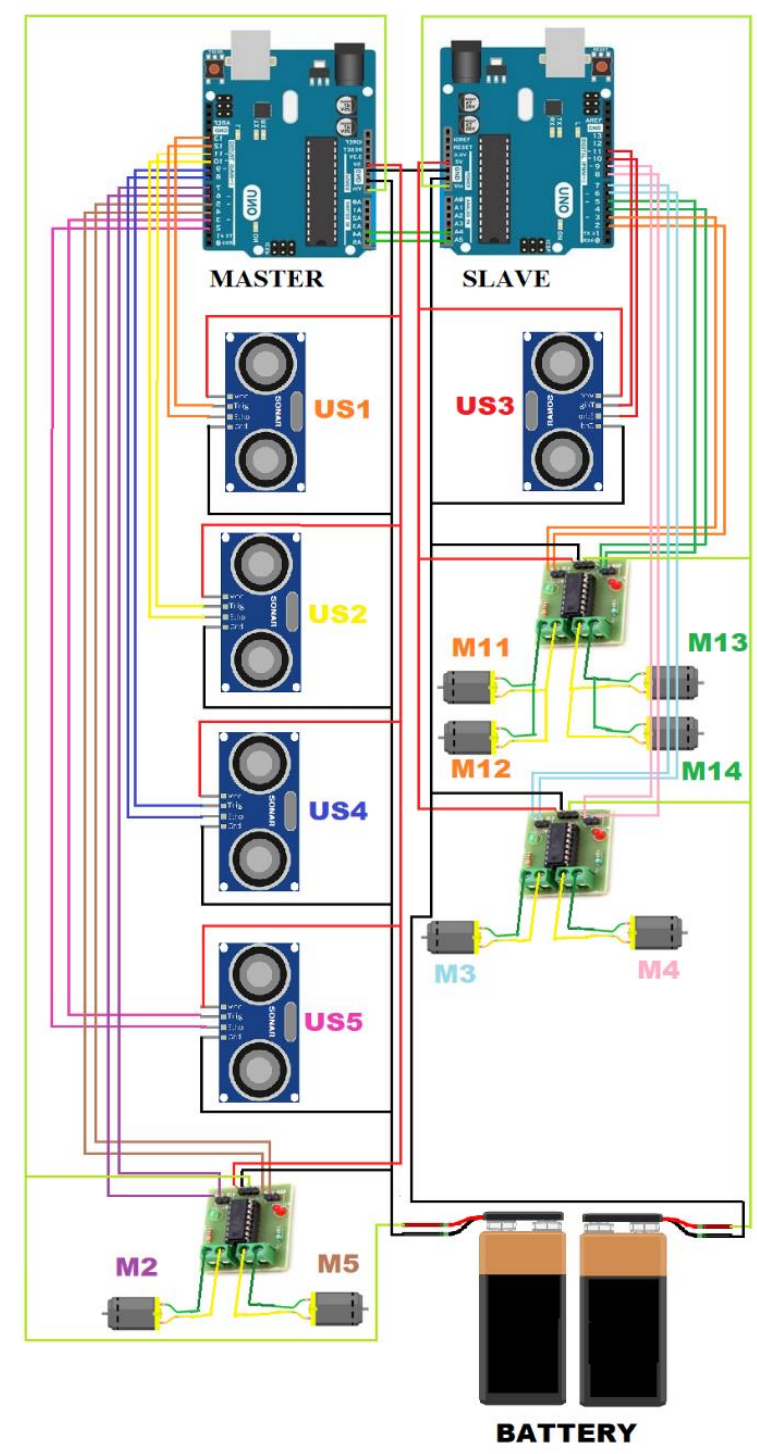

Fig 11. Complete Connection

\section{SIGNIFICANCE AND SCOPE}

\section{A. Necessity}

The idea/necessity seen for this project comes from a real incident. The project deals with a practical problem which is very common in households i.e. water bottle refiling.

Mother in houses are mostly worried for the same problem. The same incident took place on one of our group member house too. Then the idea of automatic water bottle re-filing strikes our mind.

Another incident which motivated us was that a relative of mine met an accident and the person was all alone at the house. For drinking water the filing could not be possible. With the help of our project we can tackle such simple yet most common problems.

\section{B. Applications}

The model can be used in schools, colleges, hotels etc to avoid trafficking.

$>$ In stadiums where there is very large gatherings, this will help a lot. The same thing is also possible in marriage functions, ceremonies, events, parties etc..

$>$ It will be time saving, where we can save a lot of time. We won't have to rely on anyone to fill the water bottle.

$>$ It will also be revolution for the midgets. Midgets always face difficulty in getting the water containers from the two storey fridges but with this model they will not face any difficulty in getting so.

$>$ The use of cheap components makes this project very cost effective. So if it comes in the market then it's availability will be high and affordable to all.

$>$ This model can be used in beverages and soft drinks industries. And using Arduino against PLCs makes it's chances go higher.

\section{Future Scopes}

This model can be widely used in schools, colleges, malls, hotels, restaurants etc. where gathering of people is commonly more. At these places, serving of water is the best scope that looks to be something that can be implemented. We are still not having system which serves the water filled glasses to us. So with few implementations in the flexes this can be made possible.

At the same time the use of robotic arms can also be implemented further for water saving process. The amount of water left can be put back by the arm and we can refilter it for further uses. When glass is controlled by the robotic arm then also this possibility becomes more as the arm is being controlled through the programs and with such implementation using water level indicator, this task can be done.

\section{RELATED WORKS}

There are lots of project present in today's market related to this topic but looking onto the present scenario, this project is very much feasible in the market because it is very cheap, not complex, and can be understood easily.

\section{Fully Automatic Water Tank Level Controller Magnetic Sensors}

Motor robotically switch off if no water in supply pipe or tank is full. Magnetic sensors for long life with No corrosion, carbon and oxidation of sensors and no sanitation required for installation. Moisture resistant PTH printed circuit board and water-resistant ABS plastic wall rising enclosure. Feather touch buttons and LED for water level indication and the sleek design gives your home contemporary outlook Automatic and manual mode is present. 
The SGF2/100 rotary oral liquid filler \& sealer is the automatic liquid filling machine investigated as well as produced by our company in the recent years for flattering the source development using the electrical and mechanical technique. Also this automatic liquid filling machine is utilized to fill and seal the liquid produced for health, products, machine, oral liquid preparations and also chemical, food, \& cosmetics.

\section{CONCLUSIONS}

We here conclude that our project "Automatic water Container Filler" has been successfully completed under our group and through mentor's help.

Whatever we had mentioned in our abstract we have done the same and used the procedure as mentioned earlier. Also at the same time we are highly pleased our efforts and the system is working very well.

Therefore with an automatic filling machine one can ensure speed and easy filling processes to ensure efficient filling of liquids or powders into bottles without wastage.

\section{REFERENCES}

[1]. "Getting Started: FOUNDATION > Introduction". arduino.cc.

[2]. David Kushner (2011-10-26). "The Making of Arduino". IEEE Spectrum.

[3]. Justin Lahart (27 November 2009). "Taking an OpenSource Approach to Hardware". The Wall Street Journal.

[4]. Hernando Barragán (2016-01-01). "The Untold History of Arduino". arduinohistory.github.io.

[5]. "How many Arduinos are "in the wild?" About 300,000". Adafruit Industries.

[6]. "Arduino FAQ - With David Cuartielles". Malmö University. April 5, 2013.

[7]. "The Foundation of Today's Digital World: The Triumph of the MOS Transistor". Computer History Museum.

[8]. Omura, Yasuhisa; Mallik, Abhijit; Matsuo, Naoto (2017)"MOS Devices for Low-Voltage and LowEnergy Applications". John Wiley \& Sons.

[9]. Vongsingthong, S.; Smanchat, S. (2014). "Internet of Things: A review of applications \& technologies" (PDF). Suranaree Journal of Science and Technology.

[10]. "The Enterprise Internet of Things Market". Business Insider. 